\title{
Método clínico e paradigmas da ciência
}

José A. Maia ${ }^{1}$

Houve um tempo em que a Medicina era uma prática fundamentada essencialmente na observação e na experiência, desprovida de fundamentos científicos (na acepção que o termo tem na atualidade) e transmitida diretamente do médico a seus aprendizes. Mais do que um conjunto de conhecimentos, constituía-se numa forma de viver. A doença era vista como um desequilíbrio de "humores" e "elementos" na globalidade de um ser humano individual, peculiar, indissolúvel em seu corpo e espírito. O médico procedia a uma recordação extensa da vida do doente, a anamnese, $e$ empregava todos os seus sentidos na percepção dos sinais nosológicos, no processo do diagnóstico. A seguir propunha a cura, utilizando-se não apenas de fármacos, mas de todo um conjunto de prescrições alimentares $e$ higiênicas. A relação do médico com o enfermo era intensa e perpassava todo o processo de diagnóstico e cura.

Centenas de anos mais tarde, a Medicina pretendeu tornar-se científica. Ao mesmo tempo que se apropriava do modelo biológico, em desenvolvimento exponencial a partir do século XVII, tomava emprestado o paradigma positivista da ciência, fundamentando assim o método clínico moderno. O olhar do médico cientista desloca-se do cuidado do doente para a investigação da doença, considerada então como um desarranjo em algum setor de uma máquina complexa, um desafio cuja solução encontra-se no campo da Biologia. A doença, enquanto objeto de estudo da ciência cartesiana, define-se como um problema, devendo este ser fragmentado em tantas partes quantas forem necessárias para permitir a compreensão $e$ a resolução. A primeira clivagem é realizada entre o corpo e o espírito, entre

\footnotetext{
${ }^{1}$ Professor Adjunto do Departamento de Medicina Interna da Faculdade de Ciências Médicas da UERJ; docente do Centro de Desenvolvimento do Ensino Superior em Saúde, CEDESS/UNIFESP, EPM. E-mail: jmaia@uerj.br
} 
o "somático", que constitui o universo prioritário de ações diagnósticas e terapêuticas, $e$ "o resto". Instrumentalizado por um rol extenso e detalhado de "modelos" delineados pela nosologia, o médico busca aquele no qual as anormalidades de seu paciente se "encaixem". O próximo passo consiste na reconstrução do todo a partir das partes, em conformidade com o conhecimento fisiopatológico da doença, fundamento, por sua vez, da coerência clínica. O resultado é um novo homem que só existe concretamente no conceito do médico. Um homem dividido e re-sintetizado tanto na compreensão quanto na estrutura, produto do conhecimento analítica e sinteticamente construído.

A Medicina moderna, ao substituir o ideal de cura pelo da reparação do mau funcionamento de uma estrutura determinada, transforma os processos diagnósticos. Assim, a anamnese, da viagem pela trajetória de vida do enfermo resume-se a uma entrevista dirigida, na qual a vida do indivíduo é fracionada em diversas "histórias". A leitura de um prontuário médico é, ainda hoje, um mergulho no paradigma cartesiano, revelando a investigação da doença de um ser humano por setores, agrupados sob os títulos de história da doença atual, história patológica pregressa, história fisiológica, história familiar e história social. Como peças de um quebracabeça biológico, os tópicos relatam dados objetivos a serem tratados pelo conhecimento e pelo raciocínio clínico. Assim, uma "história familiar" irá refletir o interesse do médico em detectar possíveis "pistas" de um problema a ser solucionado e não uma aproximação da estrutura familiar do paciente, de seus vínculos, raízes e valores, das condições de seu cuidado, quando de retorno ao lar.

O paradigma positivista estende a divisão das ciências naturais à especialização médica. Em que pese a possibilidade do aprofundamento de ações diagnósticas e terapêuticas, a especialização, que estreita e isola os ângulos de visão sobre o enfermo, alia-se à tecnologia, que por sua vez reduz os limites entre a estrutura corporal do paciente e o meio externo. É certo que a tecnologia amplia os sentidos humanos e estende as capacidades diagnósticas a lesões imperceptíveis por aqueles. Contudo, não raro, os exames (que deveriam ser) complementares inserem-se no paradigma cartesiano como "objetivação" de alterações diagnosticadas pela semiologia clínica. No extremo do processo situa-se o emprego da tecnologia como substituta de procedimentos clínicos.

Como não podia deixar de ocorrer, a formação médica espelha esta realidade. O paradigma positivista impregna a escola médica $e$, dialeticamente, por ela é perpetuado. As escolas tradicionais ainda hoje são pedagogicamente estruturadas com bases no relatório Flexner, que a partir de 1910 norteou o ensino médico nos Estados Unidos. A criação de um "ciclo básico" de cunho fortemente biológico, seguido por um "ciclo clínico" desarticulado do anterior, sem que haja sucessão ou integração de conhecimentos, reflete fielmente o pensamento de Comte, que afirmava que no ensino das ciências deve haver primeiramente "uma instrução fundamental sobre todas as classes de fenômenos naturais".

A reificação positivista do conhecimento manifesta-se na elaboração do currículo médico a partir de um conjunto de informações a serem 
transmitidas pelos professores e aprendidas pelos alunos. A mais simples análise das grades curriculares da maioria das escolas médicas tradicionais revela uma sucessão desarticulada de disciplinas especializadas. A fragmentação do conhecimento a ser assimilado pelo estudante coexiste com a expectativa de que este seja capaz de integrá-lo e aplicá-lo no período do internato, quando tem contato permanente com o doente e é responsável por ele.

O mesmo modelo biocêntrico que impregna a escola médica, dirige a pesquisa, enquanto produção de conhecimentos sobre as doenças como entidades "independentes", num nível progressivo de aprofundamento $e$ individualização: do sistema ao órgão, do tecido à célula, chegando, finalmente, às moléculas. A expectativa é desvendar fenômenos comuns, ou "leis gerais" subjacentes aos diversos distúrbios biológicos, que possam ser aplicadas a pacientes cujas disfunções sejam enquadráveis em suas categorias descritivas.

Ocorre, contudo, que, a exemplo da ciência, em que a visão holística do paradigma pós-moderno progressivamente se impõe, a Medicina volta a se dar conta que o homem é um todo em si, a priori, e não um "todo" resultante da reconstrução de níveis de fragmentação, que impõe e modifica limites artificiais. O conceito de doença como um processo sistêmico, que acomete um ser impossível de ser dissociado sequer em corporeidade $e$ emoções, ainda menos em parcelas orgânicas, não deixa lugar à busca etiológica de alterações pontuais, seja em que "nível" for, do órgão ao gen. O conhecimento evolui, portanto, no sentido da compreensão da transformação global sobre a compreensão estática de fenômenos distintos.

Se o pensamento cartesiano teve seu papel e valor na construção do conhecimento biológico e no desenvolvimento de uma prática clínica cientificamente mais consistente, o paradigma da ciência pós-moderna permite vislumbrar novos pressupostos que resgatem duas dimensões da unidade do ser humano. Uma, voltada para si próprio, em sua globalidade intrínseca. Outra, relativa à sua inserção no meio ambiente que o circunda, este entendido não apenas como fonte de doenças, mas também como possibilidade de promoção da saúde.

Um novo médico se delineia. Produto de uma formação mais reflexiva, integrada e humanizada. Que se aproxima do homem inteiro e compreende a doença nesta mesma dimensão holística. Capaz de integrar conhecimentos profundos com arte e técnica, termos que para os gregos antigos tinham sentidos confluentes. Um novo homem, uma nova ciência, um novo paradigma.

\section{Bibliografia sugerida}

CAPRA, F. O ponto de mutação. São Paulo: Cultrix, 1999.

CHAUÍ, M. Introdução à História da Filosofia. Dos Pré-socráticos a Aristóteles. São Paulo: Brasiliense, 1998.

SANTOS, B.S. Um discurso sobre as Ciências. 10.ed. Porto: Afrontamento, 1998.

TRIVIÑOS, A.N.S. Introdução à pesquisa em Ciências Sociais. A pesquisa qualitativa em educação. São Paulo: Atlas, 1987. 